\title{
Just picking it up? Young children learning with technology at home
}

\author{
Lydia Plowman*, Joanna McPake, Christine Stephen \\ Institute of Education, University of Stirling, Stirling, UK \\ Institute of Education \\ University of Stirling \\ Stirling \\ FK9 4LA
}

\begin{abstract}
We describe a two-year empirical investigation of three- and four-year-old children's uses of technology at home, based on a survey of 346 families and 24 case studies. Using a sociocultural approach, we discuss the range of technologies children encounter in the home, the different forms their learning takes, the roles of adults and other children, and how family practices support this learning. Many parents believed that they do not teach children how to use technology. We discuss parents' beliefs that their children 'pick up' their competences with technology and identify trial and error, copying and demonstration as typical modes of learning. Parents tend to consider that their children are mainly self-taught and underestimate their own role in supporting learning and the extent to which learning with technology is culturally transmitted within the family.
\end{abstract}

* Corresponding author. Email: lydia.plowman@stir.ac.uk 
'It's amazing that you don't have to teach them these things. They just automatically pick it up.

\section{Introduction}

During our recent study, Entering e-Society, we were struck by the number of times that parents used variants of the phrase 'just picking it up' to describe their child's learning with technology at home. The quotation above, from one of the mothers in our case studies, sums up views expressed by about three quarters of the parents: that children did not need to be taught how to use technology and their learning was effortless. Although this was a widespread belief, our household visits showed that most of the three- and four-year-old children in our study had developed a broad range of learning in their interactions with technology. In most cases, parents saw children's developing competences as a natural, unmediated process in which learning happened without teaching. The central question that we discuss in this paper is, therefore, 'How do children learn to use technologies at home if they are not explicitly taught?'

Previous accounts of older children's uses of technology in a domestic context (Facer, Furlong, J., Furlong, R. \& Sutherland, 2003; Holloway \& Valentine, 2001; Valentine, Marsh \& Pattie, $2005)$ tend to focus on screen-based media, primarily computers. So far, little attention has been paid to young children's play and learning with computers and other technologies at home (although see Marsh, Brooks, Hughes, Ritchie, Roberts \& Wright, 2005; Rideout \& Hamel, 2006), a surprising omission in light of the centrality of technologies in our everyday lives and recent interest from policymakers in the role of parents in supporting learning at home.

Research on learning in informal settings, particularly in families, describes learning as an outcome of participation in socially situated practices. Lave (1991, p. 78), for instance, refers to the ways in which 'conditions for learning flourish in the interstices of family life', suggesting that where the mechanisms of learning are not formalised or regulated they may not have high visibility. Our multiple visits to families over a period of more than a year have enabled us to consider some of these conditions for learning by addressing the following research questions:

- what are the technological resources available?

- what forms of learning are supported?

- who supports this learning?

- how do family practices contribute to this learning?

In this paper we move beyond a competence-based approach which focuses on operational skills to characterise different forms of learning with and about technology. We identify children's cultural awareness of the roles which technology plays in family life and in the wider world as an important, if frequently overlooked, area. This expanded account of learning requires an augmented description of the ways in which children's learning is supported.

Parents believed that they were not directly involved because they rarely used explicit tutoring 
but our analysis shows that the ways in which children's learning with technology is supported at home are not necessarily visible and that parents frequently underestimate their role.

The technological mediation of learning is central to this study and leads to an emphasis on the social practices around technology and associated forms of cultural transmission. Nevertheless, the study reported here has broader relevance: thinking about learning in terms of operational competences, learning dispositions, knowledge, and cultural awareness is applicable to interactions with different types of artefacts. It also gives rise to similar questions about how these interactions are supported in family settings. This entails investigating the roles of parents, siblings and other family members, and the manifestations of support which may have varying degrees of visibility.

We start by providing a brief introduction to the theoretical framework which guided this research before describing the design of the study. We then discuss our findings relating to the range of technologies children encounter in the home, the forms of learning associated with them, who provides support for learning and the manifestations of this support. We conclude by considering the implications of our findings for the development of policy and practice on learning with technology in the early years.

\section{Theoretical framework}

In our earlier studies in preschool settings we used the concept of 'guided interaction' to identify ways in which practitioners could enhance children's learning with technology (Plowman \& Stephen, 2007). Although guided interaction was not the main focus of Entering $e$-Society (which was children's development of digital literacies) it became apparent during fieldwork that the concept could provide a starting point for interrogation of the data gathered in homes. The concept is grounded in a sociocultural approach that recognises that both people and artefacts have a role in developing children's competences with technologies and that these extend beyond the operational (i.e. how to use them) to include understanding the role of technology in work and play. The centrality of the concept of tool-mediated action and the ways in which this can reveal learning (Vygotsky, 1978, p. 54-5) mean that such an approach lends itself to the analysis of technology-mediated learning. The 'tools' can be artefacts such as technologies but can also include dialogue and family practices; we have therefore conceptualised the home as both a technological landscape with differences in the provision of, and access to, technological artefacts and as a social landscape in which the family supports learning.

The sociocultural antecedents of guided interaction include theories of supported learning with a Vygotskian orientation such as scaffolding (Wood, Bruner \& Ross, 1976), assisted performance (Tharp \& Gallimore, 1989) and guided participation (Rogoff, Mistry, Göncü \& Mosier, 1993). These theories were not developed specifically for analysing technologymediated learning but they share with guided interaction an attention to mediation and the role of artefacts. The main locus of interest for scaffolding, assisted performance and guided participation is the provision of explicit support within the immediate learning environment, whereas a distinctive feature of guided interaction is that it pertains not only to these proximal adult/child encounters but also to the less visible distal elements. 
Our exploration of the sociocultural nature of learning with technology in the home takes as its starting point a recognition that an individual's learning cannot be separated from the environment in which it takes place or the cultural tools which are appropriated in the process (Cole, 1995; Gutiérrez, 2002). We focus on learning as a co-constructed outcome of the activities and cultural practices that children engage in with others, whether this is intentional or not. Much of the research literature in this tradition, including the examples cited above, acknowledges the child's agency in learning but there is still, unsurprisingly, an underlying assumption that the parent or caregiver is the main agent in providing support for learning and that this is undertaken purposefully. Our findings indicate a more complex relationship between learners and teachers than this and we draw on Lave and Wenger's (1991) account of legitimate peripheral participation to discuss learning that is described as 'just picking it up'.

This study investigates learning in the family rather than in formal educational settings. Policymakers tend to conceptualise family learning as the provision of planned courses for parents, often on how to involve their children in numeracy and literacy activities (Ofsted, 2000), or reading with children at home and encouraging homework (DfES, 2003, p.8). However, consistent with a sociocultural approach, we consider family learning to consist of the intergenerational, informal practices that suffuse family activities.

\section{Design of the study}

As shown in Table 1, we collected three main types of evidence: results from a survey, a set of case studies, and consultation with preschool and primary education professionals and policymakers.

Table 1 about here Summary of data collection

The research focus was on three- and four-year-old children identified through the preschools they attended. Children in Scotland start school at the age of five and government-funded preschool education is made available to all children on a part-time basis in the two years before they begin school. In order to ensure that the survey included a wide range of families, we recruited ten preschools, located in small towns, semi-rural settings and urban areas of multiple deprivation in central Scotland, to distribute a total of 800 questionnaires to all parents of three- and four-year-olds on our behalf. We received replies from 346 parents, a response rate of $43 \%$. In addition to some attitudinal questions which provided an initial exploration of parents' views of young children's involvement with technology, the survey produced basic demographic data which enabled us to categorise families with household income of over $£ 20 \mathrm{k}$ per annum as of advantaged socioeconomic status and those with income of less than $£ 20 \mathrm{k}$ per annum as of disadvantaged socioeconomic status. Different levels of technology were assessed based on ownership of a computer with internet access, mobile phone and interactive television at the time of the survey.

All survey respondents were invited to take part in the case-study phase and 74 volunteered. From these, 24 families were selected to ensure that the sample included roughly equal numbers of families according to the three main variables of socioeconomic status, high or low use of technologies and gender of child, as shown in Table 2. Survey data were analysed using SPSS to generate frequencies and cross-tabulations, focusing in particular on differences 
between 'disadvantaged' and 'advantaged' families, and between girls and boys. More information on these aspects of the study is available in McPake, Plowman and Stephen (forthcoming).

Table 2 about here

Characteristics of the case study sample

Nineteen out of the 24 case-study families remained involved for the full five visits over about fifteen months. The case studies enabled us to probe the survey data, identify variations and similarities across the sample, and explore the sociocultural dimensions of learning with technology by using methods which enabled us to focus not solely on behaviour or on the individual, but also on the links between learning and culture brought about by interactions involving families, artefacts and the environment. Although systematic video recordings would have enabled us to document some of these complex interactions (Plowman \& Stephen, in press), our home visits did not generally coincide with children's spontaneous use of technology and so we observed and recorded children using various self-selected items on an opportunistic basis. This approach was supplemented by producing technology maps of their homes in conjunction with the children and using photographs taken by parents and children as a stimulus for conversation (Stephen, McPake, Plowman \& Berch-Heyman, forthcoming). For data that enabled us to make judgements about attitudes to technology and for accounts of unobserved activities and experiences we relied on semi-structured interviews with parents and conversations with children (see Table 1 for the main focus of each round of visits). As a means of eliciting their attitudes to technology parents were also asked to respond to a set of statements, derived from our earlier interviews and discussions in the media, which were presented on laminated cards.

Multiple visits gave us the opportunity to gain an understanding of family cultures, develop relationships of trust, and track changing patterns of use and attitudes. Facilitated by NVivo, our analyses of the case study data were subject to detailed case-by-case readings of the data: the cases were representative in the sense that they highlighted some of the complexities of children's experiences with technology at home but the particular configurations of socioeconomic status, availability of different types of technology, and participants' attitudes and experiences were unique. Nevertheless, evidence from our case studies was contextualised by the survey data and we were able to check our emergent findings over several rounds of data collection. The expert forum (which is not reported here) produced additional data which played a role in triangulating our initial analyses.

\section{What are the technological resources available?}

Data from the survey in 2005 show that almost all of the children aged three or four were growing up in homes in which a range of technologies were in use, although not necessarily determined by socioeconomic factors. Most of our survey respondents' children were living in households where there was access to a mobile phone (98\%) and a television with interactive features (75\%). Internet access was unequally distributed, however: while over four fifths $(82 \%)$ of the more advantaged families had access, just over half $(56 \%)$ of the less advantaged respondents did so. Availability in the home did not necessarily lead to use by the children as 
two-thirds of children living in homes with an internet connection made use of it. This was mainly for the purpose of looking at websites and for nearly all $(90 \%)$ children this was while they were supervised, although $10 \%$ used websites on their own. About half of the children with access to a mobile phone used it, typically with adult help, and a similar proportion used interactive television if it was available in the house.

Although the survey provided data on the presence of key technologies in the home it did not provide detail on the range of technologies or how children used them. Analysis of the casestudy data showed that most children had access to toys that simulate appliances such as mobile phones, laptops and games consoles as well as non-technological toys: at the beginning of the visits all but three of the 24 case-study children had their own games console which connected to the television (such as V-Tech Smile, Disney Plug-n-Play or PlayStation), handheld game (such as Leapster, Nintendo or Game Boy), play laptop, or interactive book (such as LeapPad). All children encountered a wide range of leisure technologies such as television and DVD players, as well as cameras and MP3 players. About one third of the casestudy children were enthusiastic users of technology according to their parents; others had sporadic or limited interest and preferred other activities, such as dressing up or outdoor play. All except two of the children expressed an interest in technology at the beginning of the study and, according to individual interest and opportunity, enjoyed activities such as taking and sharing digital photographs or playing games on children's websites, mobile phones or handheld devices.

\section{What forms of learning are supported?}

In Interplay, our study of children and technology in preschool settings, we identified three main areas of learning: acquiring operational skills, extending knowledge of the world, and developing dispositions to learn (Plowman \& Stephen, 2007). The present household case studies revealed that children typically acquired competences in these three areas at home, too: operationally, children had learnt to switch items off and on, rewind, fast-forward and navigate websites. In terms of extending knowledge of the world, children were using technology to support the development of early literacy and numeracy or information-gathering. Dispositions to learn were enhanced through the opportunities for developing independence, sustaining attention, building confidence gained from accomplishment, and learning to follow instructions.

Although these areas of learning are not designed to be exhaustive (learning through technology-supported physical play is not included, for example) our analysis of children's engagement with the broad range of resources to which they had access at home, combined with the variety of family activities and interests in which they participated, suggested that this categorisation was too restrictive. We defined an additional area, which we referred to as cultural awareness, as children's understanding of the roles which technology plays in family life and in the wider world, and their ability to harness this understanding for a range of social and cultural purposes. This area of learning was originally identified in an earlier home-based study, Already at a Disadvantage? (McPake, Stephen, Plowman, Sime \& Downey, 2005), but our understanding of it was elaborated in the study reported here, based on interviews with parents, conversations with children and observations. Cultural awareness of technology's role included understanding and participating in activities such as watching television programmes 
and DVDs, using this awareness to take photographs and play digital games, or to use objects as props for pretend play. Children demonstrated to parents that they understood that digital technologies could be used to communicate with friends and relatives by phone (voice, texting and picture messaging), by webcam and by email, even if they were not able to use all of these modes of communication unassisted.

As it became apparent during the course of the case studies that some parents found it difficult to conceptualise their children's activities as learning, or actively preferred to think of technology in terms of its entertainment value, we found a fruitful approach was to ask 'Has your child done anything with technology since our last visit that you didn't realise they could do?' All parents responded with examples, including children rewinding a video in slow motion, locating cable television channels, resizing a window on a website, and using digital cameras or a laptop's trackpad in a controlled manner. Some parents commented on their children's use of terminology and reported children using words such as 'pause', 'desktop' and 'load', demonstrating awareness of web addresses on television programmes or asking for a site to be saved in 'Favourites'.

We also developed activities to probe the children's perspective on learning to use technology. They were presented with a picture of a child of the same sex and were asked to tell us how easy or difficult it would be for Ben or Lucy to learn how to use each of three or four pictured items and who s/he could ask for help. Not every child was able to understand this exercise but children were only presented with pictures of items that we knew they played with and there was a high degree of recognition. Games on children's websites were generally considered to be easy to use, although some children commented that parents were needed to switch on the computer or access the sites. In cases where items were considered to be difficult it was usually operational skills that were identified as the hurdle, such as knowing which button to press or how to switch something on. Some children nominated themselves to help Ben or Lucy but parents were most often cited as a source of help, followed by brothers and sisters.

\section{Who supports learning with technology at home?}

The case studies revealed that a wide variety of people were supporting learning in the home, sometimes simply by being engaged in their own activities. They included children, such as older siblings and cousins, as well as parents, grandparents, other relatives and family friends. Children could see adults recording family occasions with a digital video camera, going online to order shopping or book a holiday or making use of different leisure technologies. Older siblings were making calls, playing games or taking photos with their mobile phones, chatting on MSN, downloading music or using games consoles. These activities and technologies formed a backdrop to children's lives: the computer, for instance, was located in a spare room, a space under the stairs or a living room and so it was easily accessible to all members of the family in two-thirds of the case-study households.

Family members bought children LeapPads, VTech Smile games consoles or portable DVD players as Christmas and birthday presents and invested time in showing the child how to use them. The main source of guided interaction for using these items did not need to be a high user: grandparents, for example, could be low users but had more time available to tutor children. Other facilitators, such as older siblings, could be high users of the computer and 
games consoles but, for this reason, they also acted as inhibitors of learning by controlling access to the technology or, in two cases, carrying out tasks for their younger siblings ('he's her remote control') thereby restricting opportunities for learning. The presence of older siblings also meant that not only was there competition for resources but also that younger children were more likely to be introduced to activities that parents considered to be unsuitable, or to have access to items at an earlier age than their siblings. For some children, cousins and older siblings were an important source of hand-me-down games consoles and software as well as expertise.

No clear-cut gender divide was reported in terms of provision of guided interaction by mothers and fathers, although it should be noted that lone mothers accounted for seven of the 24 households and that, in most cases, our data are based on interviews with the mothers. About half of the parents provided explicit help to show children how to set up the computer and the television but they also reported themselves as helping to identify and access websites, view photos on a mobile phone or take pictures with a digital camera. Used by more than two-thirds of the children at the start of the study, televisions and DVD players functioned as an entry activity as they were perceived to be safe in terms of unsupervised viewing as well as easy to use once set up, a necessary task in the majority of households which had interactive television with a subscription to satellite or cable services. Channel selection could be complex, particularly if a DVD or video player was connected, as it necessitated use of the remote control and recognition of symbols and numbers. However, these technologies provided maximum return on the adult investment of proximal guided interaction so that children could become independent users and occupy themselves without disturbing parents from domestic tasks or leisure activities. In addition to encouraging independent use, the motivation for this tutoring was based on safety concerns (the need for an electricity supply meant that televisions and computers were potentially more hazardous than battery-operated equipment) and the desire to avoid the alteration of settings in such a way that they could not easily be retrieved.

Use of any of these technologies, whether adult- or child-oriented, could be turned into learning opportunities if seen as appropriate or in response to children's inquisitiveness: twothirds of parents agreed with the statement 'I expect my child to learn to use the technologies I use every day', for instance. Our observations suggested that family members felt no inhibitions about being directive and children's operational skills could be developed as a result of explicit instruction. This form of guided interaction took place in the proximal dimension as explaining and demonstrating technical skills, and interpreting rules and instructions, required face-to-face interaction at the site of engagement. Distal guided interaction in the form of peripheral vision was often used for overseeing safety and ensuring that children were not getting stuck. However, children sought help when needed and parents had an incentive to be responsive if it prolonged the time that children could be engaged in an activity. As they tended to spend longer periods at home, mothers were more likely to keep an eye on activities from afar but both parents reported being equally interested in encouraging independent use and providing access to resources.

\section{How do family practices contribute to learning?}

Interviews suggested that family practices were mediated by parents' beliefs about young children and technology. These ethnotheories (Brooker, 2003; Harkness \& Super, 1995), or 
cultural belief systems, were generally based on parents' earlier experiences of technology at school, further education or work, as well as public debate about the role of technology in the lives of young children. This debate, given prominence in the media, gives voice to the expression of anxieties about the ways in which childhood is being transformed by technology, often claiming that children's cognitive, emotional and social development is threatened (Plowman, McPake \& Stephen, under review).

More than three-quarters of the case-study families agreed with the statement 'I don't think about introducing my child to new technologies - we just use what we want to for pleasure and convenience'. This suggests that they expected their children to learn about the technologies in daily use without coaching but there was some inconsistency in this position given that more than half agreed with the statement 'I wish I knew more about new technologies so I could help my child'. The picture that emerged was one in which all families used limited explicit tutoring but they were also unknowingly demonstrating uses of technology on a day-to-day basis such that children were believed to 'just pick it up'. Three-quarters of the case-study families used this expression or its equivalent when discussing their child's use of technologies and parents often commented that they did not know how children had developed various competences. Parents rarely attributed the development of children's learning in this area to the nursery and so the source of their learning appeared to be a mystery. Our earlier studies in nurseries (Plowman \& Stephen, 2005) suggested that children had limited opportunities for learning with technology at preschool and this was reinforced by the child participants in the study reported here.

In Table 3 below, we present four categories of ways in which children were believed to 'pick up' technological competences. Based on analysis of interviews with parents, a selection of examples is used to illustrate these approaches to learning: being self-taught, trial and error (a sub-set of being self-taught), copying, and learning from demonstration by others. The examples mainly refer to operational learning because the outcomes were more obvious to parents than the development of learning dispositions or extending knowledge of the world. The information in brackets indicates the socioeconomic status of the household and whether they had high or low levels of technology at the start of the study. The findings reported here have not focused on these variables but McPake et al. (forthcoming) conclude that they did not find a direct relationship between socioeconomic disadvantage and children's opportunities to learn to use technology either in this study or the earlier Already at a Disadvantage? Although low income may influence expenditure on technologies, or parents' exposure to computers at school or work, this does not necessarily translate to impoverished experiences for children. Stated enthusiasm for the educational benefits of technology did not correlate neatly with socioeconomic status or even levels of technology.

Table 3 about here

Examples of the ways in which children 'pick up' learning with technologies

Although the outcomes were visible inasmuch as children showed evidence of increased operational skills or knowledge of the world, the illustrations in Table 3 make clear that the ways in which learning was supported were mainly invisible to their parents. The exceptions to this were when the process of 'picking it up' was a consequence of a procedure being 
demonstrated, or could be attributed to copying others, as the roles of teacher and learner were more obvious in these circumstances. However, these modes of learning were cited less frequently and, as indicated above, there was a widespread belief that the children were selftaught and that learning happened, in the words of one mother, 'by default'. A key characteristic of this natural process of 'just picking it up' was speed. When provided, tutoring was not a protracted activity in the same way as teaching a child to read, write, complete a jigsaw or ride a bike. Many parents commented on how quickly their children could grasp what they needed to do when confronted with a new family purchase or a present and that it required just a one-off demonstration ('she took to it straight away', 'they learn really quickly', 'you only have to show him once').

Demonstration was motivated by a desire to encourage a child's independent use or was a response to a direct request for help but parents did not necessarily consider this to be teaching or to be aware of the extent to which they modelled behaviour. By providing an example to follow or to imitate, modelling is central to guiding interaction and entails using technologies in a way that is consistent with real life activities. In the home, such authentic activities were commonplace and children's learning was characterised as 'just picking it up', perhaps because parents associated teaching with verbal instruction and discounted the role of showing rather than telling. Although children were not always as proficient as their parents believed, this approach seemed effective in the home as children developed competences across the four areas of learning indicated earlier. The observations and interviews showed that children were engaging in a wide range of activities at home, with many different technologies, with a variety of family members and friends, sometimes for extended periods of time. If, as parents claimed, their children were not being taught, how were they learning?

\section{Discussion}

A number of researchers in the sociocultural tradition have discussed the ways in which learning can take place without an obvious source of teaching. For instance, Rogoff et al. (2003, p. 187) described a tradition of 'intent participation' in which children learned by observing and listening-in. Experienced people

play a guiding role, facilitating learners' involvement and often participating alongside learners - indeed, often learning themselves. New learners in turn take initiative in learning and contributing to shared endeavors, sometimes offering leadership in the process.

We found that children's individual preferences, interests and dispositions were important influences on what and how they learned; they were exercising agency by watching purposefully, copying, and absorbing family practices. Nevertheless, it is not clear that the children in our study were 'intent' in their learning. Unlike the Mayan communities in which Rogoff has conducted research, the families we visited did not stress children's responsibility for learning. Indeed, parents did not seem to be aware of the potential of children's observation and were surprised at what they could do when prompted to consider their learning. Parents were happy for children to participate in household activities, unless they were worried about equipment being damaged or encountering unsuitable material, but this was not identified as a means of learning. 
Our discussions with parents and visits to the households suggest that children learnt by observation and through the cultural transmission (Lave, 1996) brought about by this unintentional modelling, so developing an awareness of technology's function in people's lives. Teaching, or what Lave (ibid.) calls 'intentional' transmission, was infrequently intentional and often incidental but the lack of explicit teaching did not lead to a lack of learning opportunities. Lave (1991, p. 71) suggests that 'in circumstances where ongoing everyday activity provides structuring resources for learning' it is rarely the case that individuals must 'take the initiative in getting someone to teach them in order to learn'.

Researchers on children's emergent literacy make reference to the importance of the examples of text that children see all around them, known as environmental print. Constant exposure to print through slogans on tee shirts, advertising, packaging and road signs can develop children's understanding of its role and value (McGee, 1986). The omnipresence of print has some parallels with the increasing presence of technology in children's lives and we use the term 'environmental technology' to suggest the ways in which it can fulfil a similar role in developing children's understanding of its sociocultural significance. In the same way that environmental print can provide a context for shared talk, environmental technology provided opportunities for children to interact with family members, creating a link between family culture and children's learning.

In the home, the broad exposure to the structuring resources provided by environmental technology and family practices meant that children appeared to learn naturally and without explicit tutoring. Parents and other adults, as well as children, were demonstrating all three areas of learning we identified in preschool settings (operational, by acquiring technical skills; extending knowledge of the world, by finding and developing information; dispositions to learn, by finding pleasure in these activities and, sometimes, learning the need for persistence) as well as learning about the cultural roles of technology. So although parents tended to recognise only operational learning, they were providing many opportunities for learning to take place. This provision of structural resources and the cultural transmission to which Lave refers illustrated how guided interaction can take place in the distal dimension.

Lave and Wenger's (1991) account of legitimate peripheral participation is useful for thinking about learning that is perceived to be 'just picking it up'. Although the examples they give are of adult learners (tailors, midwives, recovering alcoholics, quartermasters, meat cutters) they comment that 'children are, after all, quintessentially legitimate peripheral participants in adult social worlds' (p. 32) and that 'there is very little observable teaching; the more basic phenomenon is learning' (p. 92). They describe legitimate peripheral participation as:

a way to speak about the relations between newcomers and old-timers, and about activities, identities, artefacts, and communities of knowledge and practice. A person's intentions to learn are engaged and the meaning of learning is configured through the process of becoming a full participant in a sociocultural practice. This social practice includes, indeed it subsumes, the learning of knowledgeable skills. (p. 29) 
This prompts consideration of the issue of the relationships between 'newcomers' and 'oldtimers'. On the face of it, the young children were clearly the newcomers and their parents were the old-timers inasmuch as adults bear some responsibility for their children's learning. However, some parents believed that children had greater proficiency with technologies than adults. What was seen as a natural competence was based on what parents perceived as children's greater confidence and affinity for technology, and this accounted for the ways in which children could 'pick up' their expertise. Some parents were daunted by the ways in which this enabled their children to learn by trial and error and saw themselves as being 'overtaken' and needing to keep one step ahead of their children's growing abilities. In this respect, adults could also be seen as 'newcomers' and the traditional relationship between parents/teachers and children/learners was perturbed. These children were three and four years old so, in most cases, these beliefs about children's competences were based on parents' underestimation of their own expertise and role in supporting their children's learning. Nevertheless, this perceived lack of know-how may have contributed to a reticence by some parents to be involved in direct instruction, or what they saw as teaching, especially if their older sons and daughters could perform this role for them.

\section{Conclusion}

Our research suggests that young children acquire a wide range of competences when interacting with technology in the home but these were developed in ways which were not necessarily the result of direct teaching. Children's experiences at home introduced them to the use of technology for communication, self-expression, work-related tasks and entertainment, and so started to prepare children for a life in which technology would play an important role. This perspective is in line with recent research which has identified family practices as influential in the preparation of young children for school (Bennett, Weigel \& Martin, 2002; Vincent et al., 2004). Our findings on parental attitudes and family practices also seem to be consistent with other research. In the UK, a survey of over 1800 parents of children under six (Marsh et al., 2005) found that children were immersed in practices relating to popular culture, media and new technologies and developed a wide range of skills, knowledge and understanding of the digital world. Research based on a series of focus groups and a survey of over one thousand parents with children aged six months to six years old in the United States (Rideout and Hamel, 2006) provides detailed data to show the ways in which technologies have become 'part of the fabric of daily life' for young children (p.4). The study found that parents do not introduce technologies into their children's lives so much for the educational benefits as for the benefits it offers parents: 'uninterrupted time for chores, some peace and quiet, or even just an opportunity to watch their own favorite shows' (p.5). We found that parents did not routinely characterise their children's activities as learning and had limited awareness of the ways in which families supported this learning, particularly in terms of learning dispositions and cultural awareness, but it is not our intention to suggest a deficit model of parenting. The purpose of this research is not to point to the ways in which families should support learning, or to inform programmes to promote family learning, but to describe and analyse the practices that lead to children's learning without such interventions.

The main findings of our investigation of children's learning with technology at home are that: 
- preschool children have typically acquired basic levels of competence in four main areas of learning with technology (acquiring operational skills, extending knowledge of the world, developing dispositions to learn and understanding its cultural role) by the time they are ready to start school

- the home consisted of technological and social landscapes in which family practices were modelled, shaped and transmitted. The facilitators for the child's learning included interactions between resources from the social landscape of the home (grandparents, other relatives, family friends, older siblings, and parents) and resources from the technological landscape (environmental technology)

- children's learning took place as a result of trial and error, observation and copying, in addition to demonstration by more able others, and their individual preferences, interests and dispositions were important influences on the activities they chose

- parents expressed the belief that children's competences with technology were mainly the result of being self-taught and they were unaware of the ways in which they supported their child's learning by modelling uses of technology and providing opportunities to participate in and observe authentic activities

- the child's preschool was not perceived as a source of learning with technology by the parents or the children.

Educational policy documents (Learning and Teaching Scotland, 2003; QCA, 2005) draw attention to the importance of children's home experiences with technology but previous research has not so far described the nature of these experiences or the ways in which they might inform practice. This study has identified a number of areas for consideration when further development of policy in this area is planned. These include:

- recognising that children will start school with diverse experiences of using technologies, involving not only computers but also a wide range of domestic leisure technologies and electronic toys

- acknowledging the cultural awareness of technology that children develop within their families

- developing an understanding of the nature of children's existing technological competences and how these can inform the educational goals of ICT policy for preschool and the early years of primary education.

In terms of practice, the implications of this study include:

- thinking about ways in which teachers can differentiate the experiences with which children start school when considering their learning with technology

- shifting the current focus on skills towards this broader range of competences, awareness and dispositions

- providing a learning environment rich in 'environmental technology'

- recognising the importance of authenticity for children's learning.

We have characterised children's experiences with technology as entertainment and fun, leading to participation in family life and both incidental and purposeful learning. Families 
acquired technologies for different purposes, and the children were thus being inducted into different sets of cultural practices, ranging from taking digital photos of the family pets to role playing with a non-functioning mobile phone. As an important site of learning the home provides opportunities for children to both observe and participate in authentic activities and to develop a sense of the cultural value and role of technologies. The technological landscape of the home meant that children were constantly aware of environmental technology and its many uses. Combined with the influence of family culture and interaction with others, whether explicitly for the purposes of teaching or not, there was rich potential for learning.

\section{References}

Bennett, K., Weigel, D. \& Martin, S. (2002). Children's acquisition of early literacy skills: Examining family contributions. Early Childhood Research Quarterly, 17 (3), 295-317.

Brooker, L. (2003). Learning How to Learn: Parental ethnotheories and young children's preparation for school. International Journal of Early Years Education, 11 (2), 117-128.

Cole, M. (1996). Cultural Psychology: A once and future discipline. Cambridge MA: Harvard University Press.

DfES (2003) The impact of parental involvement, parental support and family education on pupil achievements and adjustment. Department for Education and Skills, Research Report 433, London.

Facer, K., Furlong, J., Furlong, R. \& Sutherland, R. (2003). Screenplay: Children and computing in the home. London: Routledge.

Gutiérrez, K. (2002). Studying cultural practices in urban learning communities. Human Development 45 (4) 312-321.

Harkness, S. \& Super, C. (Eds.) (1995). Parents' cultural belief systems: Their origins, expressions and consequences. NY: Guilford.

Holloway, S. \& Valentine, G. (2001). 'It's only as stupid as you are': Children's and adults' negotiation of ICT competence at home and at school. Social and Cultural Geography, 2 (1), 25-42.

Lave, J. (1996). Teaching, as learning, in practice. Mind, Culture and Activity, 3 (3), 149-164

Lave, J. (1991). Situating learning in communities of practice. In L. Resnick, J. Levine \& S. Teasley (Eds.), Perspectives on socially shared cognition (pp. 63-82). Washington DC: American Psychological Association.

Lave, J. \& Wenger, E. (1991). Situated learning: Legitimate peripheral participation. Cambridge: Cambridge University Press.

Learning and Teaching Scotland (2003). Early learning forward thinking: The policy framework for ICT in early years. Dundee: Learning and Teaching Scotland.

Marsh, J., Brooks, G., Hughes, J., Ritchie, L., Roberts, S. \& Wright, K. (2005). Digital beginnings: Young people's use of popular culture, media and new technologies. Sheffield: University of Sheffield.

McGee, L. (1986). Young children's environmental print reading. Childhood Education, 63 (2), 118-125.

McPake, J., Plowman, L., Stephen, C. (forthcoming). Digitally divided? An ecological investigation of young children learning to use ICT. Early Childhood Development and Care. 
McPake, J., Stephen, C., Plowman, L., Sime, D. \& Downey, S. (2005). Already at a disadvantage? ICT in the home and children's preparation for primary school. Coventry: British Educational Communications and Technology Agency.

Ofsted (2000) Family learning: a survey of current practice. Office for Standards in Education, London.

Plowman, L., McPake, J. \& Stephen, C. (under review). The technologisation of childhood? Young children and technologies at home. Submitted to Children and Society.

Plowman, L. \& Stephen, C. (in press). The big picture? Video and the representation of guided interaction. British Educational Research Journal.

Plowman, L. \& Stephen, C. (2007). Guided interaction in pre-school settings. Journal of Computer Assisted Learning, 23 (1) 14-21.

Plowman, L. \& Stephen, C. (2005). Children, play and computers in pre-school education. British Journal of Educational Technology, 36 (2) 145-158.

Qualifications and Curriculum Authority (QCA) (2005). ICT in the foundation stage. London: QCA.

Rideout V. \& Hamel E. (2006). The Media Family: Electronic Media in the Lives of Infants, Toddlers, Preschoolers and Their Parents. Menlo Park, CA: Kaiser Family Foundation.

Rogoff, B., Paradise, R.,- Arauz, R., Correa-Chávez, M. \& Angelillo, C. (2003). Firsthand learning through intent participation. Annual Review of Psychology, 54 (February), 175203.

Rogoff, B., Mistry, J., Göncü, A. \& Mosier, C. (1993). Guided participation in cultural activity by toddlers and caregivers. Monographs of the Society for Research in Child Development, 58 (8, Serial No. 236).

Stephen, C., McPake, J., Plowman, L. \& Berch-Heyman, S. (forthcoming). Learning from the children: Exploring preschool children's encounters with ICT at home. Journal of Early Childhood Research.

Tharp, R. \& Gallimore, R. (1989). Rousing minds to life: Teaching, learning and schooling in social context. Cambridge University Press, Cambridge.

Valentine, G., Marsh, J. \& Pattie, C. (2005). Children and young people's home use of ICT for educational purposes: The impact on attainment at key stages 1-4. (Research report RR672). Nottingham: Department for Education and Skills.

Vincent, C., Ball, S. \& Kemp, S. (2004). The social geography of childcare: Making up a middle-class child. British Journal of Sociology of Education 25, (2) 229-244.

Vygotsky, L. (1978). Mind in society: The development of higher psychological processes. Cambridge, MA: Harvard University Press.

Wood, D., Bruner, J. \& Ross, G. (1976). The role of tutoring in problem solving. Journal of Child Psychology and Psychiatry 17 (2), 89-100.

\section{Acknowledgments}

Entering e-Society: Young children's development of e-literacy was funded by the ESRC's eSociety programme (award RES-341-25-0034). We are grateful to the researchers, Sarah Berch-Heyman and, in the early phase, Konstantina Martzoukou, and to the families who welcomed us into their homes. Further information and papers related to this research are available from www.ioe.stir.ac.uk/research/projects/esociety/. 


\section{Authors' Biographies}

The authors are based in the Stirling Institute of Education, University of Stirling. Lydia

Plowman is Professor of Education, Joanna McPake is Senior Researcher and was Principal Investigator of Entering e-Society, and Christine Stephen is a Research Fellow and convenor of the ESRC seminar series Critical Issues for Preschool Education: Towards a Research Agenda. 


\title{
Table 1: Summary of data collection in Entering e-Society
}

\author{
Survey: June \& September 2005 \\ Focus: demographic information; audit of technology in the home; attitudes to \\ technology and children's use \\ Response rate: 346 responses from parents from 10 preschools ( $43 \%$ response rate)

\section{Case Studies:} \\ Round 1: July-Oct '05 \\ Focus: demographic information; technology audit; family usage \\ Round 2: Dec '05-Jan '06 \\ Focus: parents' educational background \& experience of technology at school, work and \\ home; child's experience of technology at nursery; attitudes to technology \& \\ expectations for future \\ Round 3: Mar-Jun ' 06 \\ Focus: parent's and child's perspectives on technologies; child's uses, prompted by \\ photographs taken by families; demonstration by child \\ Round 4: Jun-July ' 06 \\ Focus: child's non-technological activities; preparation for transition to school; mapping \\ location of technologies in the home \\ Round 5: Nov' $06-J a n$ ' 07 \\ Focus: changes in technology ownership and practices; family rules for technology use; \\ experience of transition to school where appropriate \& use of technology there; \\ activities to articulate child's perspectives on learning to use technologies
}

Expert Forum: March 2007

Focus: current perspectives on the use of ICT in preschool playrooms and the early years of primary school across the UK; reactions to our emerging findings and implications for future policy and practice in preschool and primary school. 
Table 2: Characteristics of the case-study sample in Entering e-Society

\begin{tabular}{|l|l|}
\hline Gender of focal child & Case studies \\
\hline Age at start & $\begin{array}{l}11(46 \%) \text { female } \\
13(54 \%) \text { male }\end{array}$ \\
\hline Technology status & $\begin{array}{l}7(29 \%) \text { age } 3 \\
16(67 \%) \text { age } 4 \\
1(4 \%) \text { age } 5\end{array}$ \\
\hline Family composition & $\begin{array}{l}13(54 \%) \text { high technology } \\
11(46 \%) \text { low technology }\end{array}$ \\
& $\begin{array}{l}17(71 \%) \text { two parent families } \\
7(29 \%) \text { one parent families }\end{array}$ \\
& $10(42 \%)$ older siblings; 8 (33\%) younger siblings \\
$6(25 \%)$ no siblings; 0 both older and younger siblings
\end{tabular}


Table 3: Beliefs about the ways in which children 'pick up' learning with technologies

\begin{tabular}{|c|c|c|}
\hline Category & Example & Source $^{1}$ \\
\hline \multirow[t]{7}{*}{ Self-taught } & $\begin{array}{l}\text { "It's amazing that you don't have to teach } \\
\text { them these things. They just automatically } \\
\text { pick it up." }\end{array}$ & $\begin{array}{l}\text { Interview, Armstrong (adv., high tech), } 4^{\text {th }} \\
\text { visit, June } 2006\end{array}$ \\
\hline & $\begin{array}{l}\text { When asked how Freddie learned to look at } \\
\text { photos on her phone mum says "he just } \\
\text { learned, he just picked it up". }\end{array}$ & $\begin{array}{l}\text { Field notes from interview, Dawson } \\
\text { (disadv., low tech), } 3^{\text {rd }} \text { visit, March } 2006\end{array}$ \\
\hline & $\begin{array}{l}\text { Alex also very good at the PlayStation... } \\
\text { Picked up how to do these games by } \\
\text { himself. }\end{array}$ & $\begin{array}{l}\text { Field notes from interview, Simmonds } \\
\text { (adv., high tech), 2nd visit, November } \\
2005\end{array}$ \\
\hline & $\begin{array}{l}\text { [Mother] bought this toy and Lewis used it } \\
\text { easily - it seemed natural. }\end{array}$ & $\begin{array}{l}\text { Field notes from interview, Macdonald } \\
\text { (adv., high tech), 2nd visit, December } \\
2005\end{array}$ \\
\hline & $\begin{array}{l}\text { Mum mentions how surprising it is that she } \\
\text { never showed Katie how to use the video } \\
\text { player but she just knows how to work it. }\end{array}$ & $\begin{array}{l}\text { Field notes from interview, Ferguson } \\
\text { (adv., low tech), 3rd visit, April } 2006\end{array}$ \\
\hline & $\begin{array}{l}\text { Mum says that David will pick up the } \\
\text { computer quite quickly. }\end{array}$ & $\begin{array}{l}\text { Field notes from interview, Cullen (adv., } \\
\text { low tech), 3rd visit, April } 2006\end{array}$ \\
\hline & "I expect him to just learn naturally." & $\begin{array}{l}\text { Response to written statements, Dickson } \\
\text { (adv., high tech), 5th visit, November } 2006\end{array}$ \\
\hline \multirow[t]{2}{*}{$\begin{array}{l}\text { Trial and } \\
\text { error }\end{array}$} & $\begin{array}{l}\text { Learned games on BBC website "just } \\
\text { through trial and error". }\end{array}$ & $\begin{array}{l}\text { Field notes from interview, Simmonds } \\
(\text { adv., high tech), 3rd visit, March } 2006\end{array}$ \\
\hline & $\begin{array}{l}\text { Mum thinks [Bob the Builder] is the first } \\
\text { game he has sat with and learned how to do } \\
\text { it "through trial and error". }\end{array}$ & $\begin{array}{l}\text { Field notes from interview, Taylor (adv., } \\
\text { low tech), 3rd visit, March } 2006\end{array}$ \\
\hline \multirow[t]{4}{*}{ Copying } & $\begin{array}{l}\text { "She does things because we do it. She } \\
\text { copies us." }\end{array}$ & $\begin{array}{l}\text { Response to written statements, } \\
\text { MacGregor (disadv., low tech), } 5^{\text {th }} \text { visit, } \\
\text { November } 2006\end{array}$ \\
\hline & $\begin{array}{l}\text { One morning she put the telly and a DVD } \\
\text { on by herself. Mum was surprised... She } \\
\text { must have been watching others do it } \\
\text { because they never showed her. }\end{array}$ & $\begin{array}{l}\text { Field notes from interview, Murdoch } \\
\text { (disadv., low tech), 2nd visit, February } \\
2006\end{array}$ \\
\hline & $\begin{array}{l}\text { [His sister] has an important role in } \\
\text { teaching Liam to use technology. He either } \\
\text { copies her or copies whatever mum and dad } \\
\text { are doing. They haven't consciously taught } \\
\text { him anything, he must have learned to use } \\
\text { websites and the mouse by copying Betty. }\end{array}$ & $\begin{array}{l}\text { Field notes from interview, Dickson (adv., } \\
\text { high tech), } 5^{\text {th }} \text { visit, November } 2006\end{array}$ \\
\hline & $\begin{array}{l}\text { She wasn't taught how to use the DVD } \\
\text { player - she learnt by watching others use } \\
\text { it. }\end{array}$ & $\begin{array}{l}\text { Field notes from interview, MacGregor } \\
\text { (disadv., low tech), 2nd visit, December } \\
2005\end{array}$ \\
\hline
\end{tabular}




\begin{tabular}{|l|l|l|}
\hline Demonstration & $\begin{array}{l}\text { Mum showed her how to use [the CD } \\
\text { player] and she took to it straight away. }\end{array}$ & $\begin{array}{l}\text { Field notes from interview, Baxter (adv., } \\
\text { low tech), 2 }\end{array}$ \\
\hline & $\begin{array}{l}\text { Says he picks things up very quickly }- \\
\text { watches a couple of times and can do it. }\end{array}$ & $\begin{array}{l}\text { Field notes from interview, Scott (disadv., } \\
\text { low tech), 2nd visit, February 2006 }\end{array}$ \\
\hline
\end{tabular}

\footnotetext{
${ }^{1}$ All family visits were made by two researchers: one audio-recorded interviews and one took field notes. Rather than transcribe tapes in their entirety, one researcher produced an account of the visit from a synthesis of information from the recording, some verbatim sequences and the field notes. This was checked for accuracy by the other researcher. Where an illustration is described as 'field notes from interview' it has been produced from this process, also used for the responses to the statements provided on laminated cards. Where the source is given as 'interview' or the material is presented within quotation marks it is verbatim. There is a disproportionate number of comments from advantaged families here because four out of the five families who discontinued involvement in the study were in this category.
} 